\title{
ANNOUNCEMENT
}

\section{THE EUGENICS SOCIETY}

\author{
Marie Stopes Research Fund
}

The Council of the Eugenics Society is prepared to receive applications for support of research* in those areas of activity for which the late Dr. Marie Carmichael Stopes through her work with the Society for Constructive Birth Control is best remembered, namely problems of:- (a) Fertility control (b) Differential fertility (c) Eugenic aspects of reproduction and population (d) Eugenic aspects of sex education and sexual behaviour and the impact of all these and related matters on the welfare of women and of the community, with particular emphasis (in keeping with the biosocial outlook of the Society) on interdisciplinary research.

The General Secretary of the Society will be pleased to provide further information and advice on the appropriate method of application. The Eugenics Society, 69 Eccleston Square, London SW1V 1PJ

* (UK-based projects only) 